\title{
Knowledge of Rights of Persons with Disability (RPwD) Act and caregiver burden in depressed parents of children with intellectual disability
}

\author{
Dhananjay S Sahastrabhude ${ }^{1}$, Maithili S Umate ${ }^{2}$, Hrishikesh B Nachane ${ }^{3}$, V.P. Kale ${ }^{4}$ \\ ${ }^{1}$ Student, Grant Government Medical College and J.J. Hospital, Mumbai \\ ${ }^{2}$ Associate Professor and Head of Unit, Department of Psychiatry, Grant Government Medical College \\ and JJ Hospital, Mumbai \\ ${ }^{3}$ Assistant Professor, Department of Psychiatry, TNMC \& BYL Nair Ch Hospital, Mumbai \\ ${ }^{4}$ Professor and Head, Department of Psychiatry, Grant Government Medical College and JJ Hospital, \\ Mumbai. \\ Corresponding author: Hrishikesh Nachane \\ Email - hbnachane@gmail.com
}

\begin{abstract}
Background: Caregiver burden and depression are related in parents of children with intellectual disability (ID), however, few Indian studies have addressed this. The Rights of Persons with Disabilities (RPwD) Act, 2016 outlines several benefits for persons with disability, but no study has looked into the knowledge parents of children with ID have about it. The present study assessed caregiver burden and the knowledge regarding RPwD Act in depressed parents of children with ID..

Methodology: The present cross - sectional, observational study recruited 50 parents of children with ID, diagnosed with Major Depressive Disorder as per DSM - 5. They were administered the Hamilton's Depression Scale (HAM - D) and Pai and Kapur's Family Burden Interview Schedule (FBIS) to assess for severity of depression and caregiver burden respectively. A semi-structured questionnaire was developed to assess knowledge of RPwD Act.

Results: $26 \%$ of depressed parents had severe caregiver burden. Severity of depression correlated positively with caregiver's and child's age. Caregiver burden did not correlate with any factor. $88 \%$ of the parents were aware about the RPwD Act and certification procedure but more than $50 \%$ did not know regarding the specific provisions. Lowest knowledge was seen regarding tax rebates (4\%), followed by reservations $(6 \%)$. Conclusion: Caregiver burden is present in approximately one - fourth of caregivers with depression. Older children and older caregivers have more severe depression. Knowledge regarding tax rebates, educational and financial benefits in the RPwD Act appears to be poor in caregivers with depression.
\end{abstract}

Keywords: Intellectual Disability, Caregiver Burden, Depression, RPwD Act

(Paper received $-12^{\text {th }}$ October 2020 , Peer review completed $-25^{\text {th }}$ November 2020 )

(Accepted $-28^{\text {th }}$ November 2020)

\section{INTRODUCTION}

Intellectual disability (ID) is defined by the presence of significant limitations in intellectual functioning and adaptive behaviour with onset before 18 years, usually at birth [1]. ID not only impairs the quality of life of the child, but puts tremendous burden on their caregivers, especially parents [2]. An intellectually disabled child demands for special and extra care even in aspects of basic life skills such as daily routine activities [3]. It naturally becomes the responsibility of the parents to meet these special demands successfully. Parents of children with ID have been shown to have significant psychopathology [4]. Azeem et al. have shown that $50-60 \%$ of parents of children with ID to have depression and anxiety [4]. Factors such as severity of ID, social isolation and behavioural disturbances in the child all have shown to correlate with severity of psychopathology [5]. Recent literature has focused on caregiver burden experienced by those caring for patients with long standing mental illnesses and disability, including ID [4-5]. Caregiver burden has been 
defined as the level of multifaceted strain perceived by the caregiver from caring for a loved one over time [6]. Increased burden of care has long lasting negative consequences, such as decreased care provision, reduced quality of life, deterioration of physical and psychological health, among others [6].

Studies all across the globe have reported significant caregiver burden in parents of children with ID [7-8]. Increased financial needs in caring for the child, with increased medical and educational demands leads to stress among parents and contributes to their burden [8]. Families with an intellectually disabled child have also reported feeling isolated from others in their society [9]. Parents have to handle repeated physical and emotional crises of the child adding to emotional distress [10]. Having a child with ID often requires a reorientation and revaluation of family goals, responsibilities and relationships [11]. This leads to several psychological disturbances in the parents, such as depression and anxiety [5]. Several factors have been implicated in development of depression and anxiety, such as burden, family stress, guilt, behavioural issues in the child, etc. [12-13]. Few studies have assessed the interplay of burden of care and depression in India, and a comprehensive assessment is lacking.

After the United Nations Convention on the Rights of Persons with Disabilities (UNCRPD), India moved towards a rights-based, biopsychosocial model of disability, which culminated in the Rights of Persons with Disabilities (RPwD) Act, 2016 [14]. This act has provided numerous rights and facilities to people with disabilities, including ID. It includes equity and non-discrimination, right to have a proper community life which will be endeavoured by the government, protection from cruelty and inhuman treatment, violence, abuse and exploitation, among others [15]. RPwD Act also specifically stresses on providing ideal educational facilities for the intellectually disabled children with inclusive schooling, scope for recreation and early detection and intervention [15]. Although various measures have been proposed and various rules have been set up under the provision of RPwD Act, the efficiency of such facilities is yet not established completely. In order to implement these provisions at ground level, it is important that the caregivers of the disabled individuals are aware about them. No significant literature is available assessing this awareness about the RPwD Act, particularly with respect to ID. Hence, the present study was formulated, which aimed to assess caregiver burden in parents of children with ID who have been diagnosed with depression, and their associated factors. We also looked into the knowledge regarding RPwD Act in depressed parents with an intellectually disabled child.

\section{METHODOLOGY}

The following study is a cross-sectional, observational study conducted in the disability clinic of the psychiatry department of a tertiary health care center in Mumbai. Ethical approval for the study was taken from the Institutional Ethics Committee (IEC/Pharm/ICMR/135/May/2019; dated 28/05/2019) and the study duration was two months (July and August 2019). Convenience sampling method was used and 50 consecutive parents of children aged six to eighteen years, diagnosed with ID (IQ $<70)$ by standard IQ tests, who visited our disability clinic and were found to be suffering from major depressive disorder as per DSM -5 criteria [16], were recruited. Parents with significant physical illness, whose children had other comorbid psychiatric or medical illness apart from ID, or those with more than one child with ID were excluded. Detailed experimental procedure was explained to them and a written informed consent was subsequently taken. A basic case record form was used to note their sociodemographic details of the parents and their child's age, sex and IQ. Awareness regarding the RPwD Act was assessed by a separate semi - structured questionnaire that was devised for this study. It mainly targeted certification procedure and benefits the parents can expect under the act. Severity of depression was assessed by Hamilton Depression rating scale (HAM -D). Pai and Kapur's Family Burden Interview Schedule (FBIS) was used for the assessment of caregiver burden. All the three instruments were translated into vernacular languages of Hindi and Marathi and back translated to English. They were approved by a team of experts for the present population of study. The entire assessment was completed in one sitting and took about $25-30$ minutes.

\section{Instruments}

- Hamilton Depression Scale (HAM-D) [17]: The 17 items HAM - D was used to assess for severity of depression. Each item is scored from $0-4$ or $0-2$. Scores of seven or less were considered 
normal, those between 8 and 16 were considered mild depression, between 17 and 23 were considered moderate depression, and scores over 24 were considered as severe depression.

- Pai and Kapur's Family Burden Interview Schedule (FBIS) [18]: This 24 item scale, commonly used to assess caregiver burden was administered. Each item is scored on a three point Likert scale. Higher scores indicate higher burden. Scores of 23 and above are deemed to have significant caregiver burden [19].

- Semi-structured questionnaire for knowledge of RPwD Act, 2016: It comprised of eight questions pertaining to the aspects of RPwD Act, 2016 that are relevant to parents of children with ID. The questions were as follows

1) Are you aware about the certification procedure of $\mathrm{RPwD}$ Act, 2016?

2) If yes, where do you think the certification procedure takes place?

3) Which mental conditions according to you need certification?

4) Are there any reservations in government job opportunities for your child?

5) Are there any tax rebates available for families of children with mental disabilities?

6) Are there any travel concessions available for your child?

7) Are there any specific educational benefits under RPwD Act that you are aware of?

8) Should your child be admitted to the same school where other intellectually normal children are admitted?

\section{STATISTICAL ANALYSIS}

Statistical Package for the Social Sciences (SPSS 20.0) was applied for statistical analysis. Data were expressed as mean plus or minus standard deviation for continuous variables and frequencies and percentages for categorical variables. Association of caregiver burden and severity of depression was done using Fisher's exact test. Correlation of independent variables with severity of depression and caregiver burden was done using Pearson's correlation test for continuous variables and Point - biserial correlation test for dichotomous categorical variables. $P$ value of less than 0.05 was considered statistically significant.

\section{RESULTS}

The average age of parents enrolled in the study was $36.30 \pm 5.46$ years. Out of the total 50 parents included in the study, 37 (74\%) were mothers, 13 were fathers $(26 \%)$. When evaluated for socio-economic status using Modified Kuppuswamy Index, $82 \%$ (41 out of 50) fell under upper lower class while remaining 18\% fell under lower middle class. Thirty seven out of 50 parents $(74 \%)$ belonged to nuclear type of family, and the remaining $26 \%$ lived in a joint family. The average age of children with ID was $10.02 \pm 3.86$ years. $60 \%$ (30 out of 50) of the children were males and the remaining $40 \%$ were females. The average IQ of the children was $44.89 \pm 14.28$. Looking into the type of ID, it was seen that $18(36 \%)$ had mild intellectual disability (IQ between 50 and 69), 21 (42\%) were having moderate intellectual disability (IQ between 35 and 49), 4 (8\%) were having severe intellectual disability (IQ between 20 and 34) and the remaining 7 (14\%) were with profound intellectual disability (IQ less than 20).

Mean score of the sample on HAM - D was $16.28 \pm 2.62$. Twenty-eight out of 50 parents (56\%) had mild depression, 21 (82\%) had moderate depression and $1(2 \%)$ had severe depression on HAM $-\mathrm{D}$. The mean score on FBIS was $19.88 \pm 4.35$. Out of 50, $13(26 \%)$ had significant caregiver burden in the sample. Using Fisher's exact test, it can be seen that distribution of severity of depression was uniform across parents with and without burden and there was no significant difference (table 1). Assessing the factors related to severity of depression in the parents (table 2), parents' age $(r=0.46, P=0.001)$ and child's age $(r=0.30, P=0.037)$ both had positive correlation with severity of depression. The strength of correlation was stronger for parental age (moderate strength) than child's age (mild strength). The other factors did not significantly correlate with severity of depression. 
Table 1: Caregiver burden and severity of depression

\begin{tabular}{|l|l|l|l|l|l|}
\hline \multirow{2}{*}{$\begin{array}{l}\text { Severity of } \\
\text { depression }\end{array}$} & \multicolumn{2}{|l|}{ Caregiver burden } & \multirow{2}{*}{ Total } & $\begin{array}{l}\text { Fisher's } \\
\text { exact test } \\
\text { value }\end{array}$ & \multirow{2}{*}{ Significance } \\
\cline { 2 - 5 } & Present & \multicolumn{1}{|l}{ Absent } & & \\
\hline Mild & $7(53.8 \%)$ & $21(56.8 \%)$ & $28(56 \%)$ & \multirow{2}{*}{2.91} & \multirow{2}{*}{0.233} \\
\cline { 1 - 4 } Moderate & $5(38.5 \%)$ & $16(43.2 \%)$ & $21(42 \%)$ & \\
\cline { 1 - 4 } Severe & $1(7.7 \%)$ & $0(0)$ & $1(2 \%)$ & \\
\hline Total & $13(26 \%)$ & $37(74 \%)$ & $50(100 \%)$ & & \\
\hline
\end{tabular}

Data expressed as $N(\%)$

Table 2: Socio-demographic factors associated with severity of depression and severity of caregiver burden

\begin{tabular}{|c|c|c|c|}
\hline Variable & Distribution in the sample & $\begin{array}{l}\text { Correlation with severity of } \\
\text { depression (HAM -D) }\end{array}$ & $\begin{array}{l}\text { Correlation with } \\
\text { burden of care } \\
\text { (FBIS) }\end{array}$ \\
\hline $\begin{array}{l}\text { Parent's age } \\
\text { (years) }\end{array}$ & $36.30 \pm 5.46$ & $\begin{array}{c}r=0.46 \\
P=0.001^{*}\end{array}$ & $\begin{aligned} r & =0.23 \\
P & =0.109\end{aligned}$ \\
\hline Parent's sex & $\begin{array}{c}\text { Male }=13(26 \%) \\
\text { Females = } 37(74 \%)\end{array}$ & $\begin{array}{l}r=-0.01 \\
P=0.965\end{array}$ & $\begin{array}{l}r=-0.04 \\
P=0.795\end{array}$ \\
\hline Type of family & $\begin{array}{c}\text { Nuclear }=37(74 \%) \\
\text { Joint }=13(26 \%)\end{array}$ & $\begin{array}{l}r=-0.07 \\
P=0.638\end{array}$ & $\begin{array}{l}r=-0.07 \\
P=0.638\end{array}$ \\
\hline $\begin{array}{l}\text { Socio-economic } \\
\text { status }\end{array}$ & $\begin{array}{l}\text { Lower middle class }=9(18 \%) \\
\text { Upper lower class }=41(82 \%)\end{array}$ & $\begin{array}{l}r=-0.15 \\
P=0.298\end{array}$ & $\begin{array}{l}\mathrm{r}=0.12 \\
\mathrm{P}=0.40\end{array}$ \\
\hline Child's age (years) & $10.02 \pm 3.86$ & $\begin{array}{c}\mathrm{r}=0.30 \\
\mathrm{P}=0.037^{*}\end{array}$ & $\begin{aligned} r & =0.05 \\
P & =0.743\end{aligned}$ \\
\hline Child's sex & $\begin{array}{c}\text { Male }=30(60 \%) \\
\text { Female }=20(40 \%)\end{array}$ & $\begin{array}{l}r=-0.17 \\
P=0.247\end{array}$ & $\begin{array}{l}r=-0.11 \\
P=0.448\end{array}$ \\
\hline Child's IQ & $44.89 \pm 14.28$ & $\begin{array}{l}r=-0.23 \\
P=0.112\end{array}$ & $\begin{array}{l}r=-0.02 \\
P=0.169\end{array}$ \\
\hline
\end{tabular}

*statistically significant

IQ - Intelligence Quotient, HAM - D - Hamilton's Depression Scale, FBIS - Family Burden Interview Schedule

Table 3: Knowledge regarding Rights of Persons with Disability (RPwD) Act in the sample

\begin{tabular}{|c|c|}
\hline Question related to RPwD Act & Response \\
\hline $\begin{array}{l}\text { Are you aware about the certification procedure of } \\
\text { RPwD Act, 2016? }\end{array}$ & $\begin{array}{l}\text { Yes }=44(88 \%) \\
\text { No }=06(12 \%)\end{array}$ \\
\hline $\begin{array}{l}\text { If yes, where do you think the certification procedure } \\
\text { takes place? }\end{array}$ & $\begin{array}{c}\text { Only Government Hospitals }=41(82 \%) \\
\text { Municipal Corporation Hospitals }=2(4 \%) \\
\text { Any hospital including private }=1(2 \%) \\
\text { Don't know }=6(12 \%)\end{array}$ \\
\hline $\begin{array}{c}\text { Which mental conditions according to you need } \\
\text { certification? }\end{array}$ & $\begin{array}{c}\text { Intellectual Disability only }=16(32 \%) \\
\text { Other disorders also (like epilepsy, etc. })=08 \\
(16 \%) \\
\text { Don't know }=26(52 \%)\end{array}$ \\
\hline
\end{tabular}




\begin{tabular}{|c|c|}
\hline $\begin{array}{c}\text { Are there any reservations in government job } \\
\text { opportunities for your child? }\end{array}$ & Yes $=3(6 \%)$ \\
No $=47(94 \%)$
\end{tabular}

When asked about the certification procedure and benefits under the RPwD Act (table 3), 44 out of 50 (88\%) of the parents claimed that they had heard about the new law, while $6(12 \%)$ responded that they had not. Eighty-two percent parents (41 out of 50) thought that the certification procedure takes place only at government hospitals, whereas two of them (4\%) thought that even municipal corporation hospitals can certify while one parent $(2 \%)$ thought that certification can take place at any hospital including the private ones. Regarding conditions requiring certification, 16 parents out of $50(32 \%)$ thought that only intellectual disability requires certification, while eight parents (16\%) thought that other conditions like epilepsy also need certification. Twenty-six parents (52\%) didn't know about the exact conditions which require certification. When asked about reservations in government jobs, only three out of $50(6 \%)$ parents said that their child could avail it, while remaining 47 (94\%) said no. Forty eight out of 50 parents $(96 \%)$ thought that there were no tax rebates available under the provisions of RPwD Act, while two of them (4\%) thought that rebates were available. $36 \%$ of the parents (18 out of 50 ) were aware about the travel concessions provided under the Act, but remaining 64\% (32 out of 50) were still unaware of the same. Same response was recorded when asked whether their children should be admitted to the same school where other intellectually normal children are admitted. Asking about the benefits revealed that 18\% (9 out of 50) parents thought that only concession in school fees is available and the rest $82 \%$ did not know about the same.

\section{DISCUSSION}

Parents of children with ID play a crucial role in overall development as well as the treatment of the child [19-20]. It has been seen that caring for an intellectually disabled child can prove to be stressful, leading to significant burden in the parents [20]. The present analysis shows that $26 \%$ of parents who had depression had severe caregiver burden, as several studies have hitherto demonstrated. Depressed patients find it difficult to cope with the increased demand of caring for a child with ID [4]. The unmet financial and emotional support as perceived in depression, is often associated with increased caregiver burden [21]. Our study, unlike others, did not find any link between caregiver burden and depression [7,20]. Guilt regarding the condition of the child and social isolation have been shown as two of the most common predictors of depression with respect to caregiver burden [7,20]. In fact, it has been found that parents of children with ID who had high depression had caregiver burden as the strongest predictor [20-22].

While child related factors such as behavior and severity of ID [7] and caregiver related factors such as parental age, marital status, and education level [21] have been shown to be associated with burden, but this was not so in our case. A small sample size could account for this. The factors that were significantly associated with depression in the parents were age of the parent and child. Similar to our findings, caregiver age has been shown to be associated with depression and anxiety in other disorders [23]. It is possible that elderly parents find it difficult to cope with the stress and hence may be predisposed to develop depression and anxiety [23]. Parents are expected to coordinate the child's multifaceted medical, educational, and developmental interventions while balancing competing family needs, and this is difficult in elderly parents [24]. Depression in parents correlated positively with child's age, indicating parents of older children have more depression. As children grow up, parents expect them to handle certain responsibilities and not being 
able to meet their personal and professional goals is a source of stress and guilt for their parents $[4,5]$. The other factors were not associated significantly.

$\mathrm{RPwD}$ Act has come up with a wide array of rights and provisions for the intellectually disabled children as well as their caregivers and families [15]. But for this Act to be implemented successfully, caregivers should be aware about all the concessions, facilities and benefits under the Act. Only $88 \%$ parents in the present sample were aware about the certification procedure. This could be because many a times schools refer patients directly to the hospital without parents understanding why they are being referred. $76 \%$ of the parents thought only government hospitals can certify, despite the Act giving permission to municipal hospitals and district hospitals to certify. Inspite of $88 \%$ of the parents being aware about the certificate procedure, very few were aware about the provisions. More than $90 \%$ were unaware regarding the tax rebates and government reservations and more than $80 \%$ were unaware regarding educational benefits. $\mathrm{RPwD}$ Act states that there should be integration of normal as well as intellectually disabled children in the same class [25], yet $64 \%$ of the parents were unaware about the same. Many schools show reluctance in including children with ID in normal classes and refer them to special schools.

Kashyap et al. had similarly found that caregivers had limited knowledge about benefits available for patients with disability as per the old PwD Act, 1995 [26]. As per their findings, 99\% of patients from rural areas did not avail any benefits other than the disability pension, while $6.6 \%$ of urban mentally retarded were availing special school education and $4.6 \%$ of the urban disabled availed income tax benefits [26]. Despite the increment in provisions and reservations for disabled patients, our analysis shows that knowledge of the Government rules and benefits still remains poor and is following similar trends as with previous Acts. Parents' mental status, and increasing burden could be probable causes for them not actively seeking provisions and benefits for their children. Thus to increase awareness of RPwD Act and utilization of the various benefits for children with ID, it is imperative to screen their parents for depression and anxiety as this can hinder help seeking. Such measures will definitely improve the utility of benefits for persons with disability.

The present study had a few limitations. Our sample size was small, which lead to several associations becoming insignificant. Other factors like social support which affect burden were not assessed in the present study. Knowledge regarding RPwD Act was not assessed by any standard instrument and the sample was solely pathological. Understanding the impact of the RPwD Act among other parents should be focused in the future.

\section{CONCLUSION}

Our study concludes that $26 \%$ of depressed parents of children with ID have severe caregiver burden. Severity of depression significantly correlates with parents' and child's age, being more severe in older parents and older children. Despite $88 \%$ of the parents being aware regarding the certification procedure under the $\mathrm{RPwD}$ Act, 2016, more than $50 \%$ are unaware about the various provisions; least regarding tax rebates and government reservations. So, nation-wide awareness programs should be designed to make parents of children with ID aware about the various facilities and rights provided by the RPwD Act. These should go hand in hand with screening measures and treatment of parents of children with ID for optimum effect.

\section{REFERENCES}

1. Schalock R, Luckasson R, Shogren $\mathrm{K}$. The renaming of mental retardation: Understanding the change to the term intellectual disability. Intellect Dev Disabil 2007;45:116-24.

2. Olsson MB, Hwang CP. Depression in mothers and fathers of children with intellectual disability. J Intellect Disabil Res 2001;45:535-43.

3. Datta SS, Russell PS, Gopalakrishna SC. Burden among the caregivers of children with intellectual disability: associations and risk factors. J Learn Disabil 2002;6:337-50.

4. Azeem MW, Dogar IA, Shah S, Cheema MA, Asmat A, Akbar M, et al. Anxiety and depression among parents of children with intellectual disability in Pakistan. J Can Acad Child Adolesc Psychiatr. 2013;22:2905 . 
5. Majumdar M, Pereira YD, Fernandes J. Stress and anxiety in parents of mentally retarded children. Indian J Psychiatry. 2005;47:144-7.

6. Schene AH, Tessler RC, Gamache GM. Caregiving in severe mental illness: conceptualization and measurement. In: Knudsen HC, Thronicroft G, editors. Mental health service evaluation. 1st ed. Cambridge: Cambridge University Press; 1996. pp 296-316.

7. Maes B, Broekman TG, Došen A, Nauts J. Caregiving burden of families looking after persons with intellectual disability and behavioural or psychiatric problems. J Intellect Disabil Res 2003;47:447-55.

8. Azar M, Badr LK. The adaptation of mothers of children with intellectual disability in Lebanon. J Transcult Nurs 2006; 17:375-80.

9. Gupta RK, Kaur H. Stress among parents of children with intellectual disability. Asia Pacific Disabil 2010;21:118-26.

10. Gohel M, Mukherjee S, Choudhary SK. Psychosocial impact on the parents of mentally retarded children in Anand District. Healthline 2011;2:62-6.

11. Karmanshahi SM, Vanaki Z, Ahmadi F, Kazemnezad A, Mordoeh E, Azadfalah P. Iranian mothers perception of their lives with children with mental retardation: A preliminary phenomenological investigation. J Dev Phys Disabil 2008;20:317-26.

12. Greenberg JS, Seltzer MM, Krauss MW, Kim H. The differential effects of social support on the psychological well-being of aging mothers of adults with mental illness or mental retardation. Fam Relat 1997;46:383-94.

13. Hastings RP. Parental stress and behaviour problems of children with developmental disability. J Intellect Dev Disabil 2002;27:149-60.

14. Balakrishnan A, Kulkarni K, Moirangthem S, Kumar CN, Math SB, Murthy P. The rights of persons with disabilities Act 2016: Mental health implications. Indian J Psychol Med 2019;41:119-25.

15. Math SB, Gowda GS, Basavaraju V, Manjunatha N, Kumar CN, Philip S, et al., The rights of persons with disability act, 2016: Challenges and opportunities. Indian J Psychiatry. 2019;61:809 - 15.

16. American Psychiatric Association. Diagnostic and statistical manual of mental disorders (DSM-5). American Psychiatric Pub, 2013.

17. Hamilton M. A rating scale for depression. J Neurol Neurosurg Psychiatry 1960;23:56-62.

18. Pai S, Kapul RL. The Burden on the family of a psychiatric patient: development of an interview schedule. $\mathrm{Br}$ J Psychiatry 1981;138:332-5.

19. Yu Y, Liu ZW, Zhou W, Zhao M, Tang BW, Xiao SY. Determining a cutoff score for the family burden interview schedule using three statistical methods. BMC Med Res Methodol 2019;19:93-100.

20. Gallagher S, Phillips AC, Oliver C, Carroll D. Predictors of psychological morbidity in parents of children with intellectual disabilities. J Pediatr Psychol 2008;33:1129-36.

21. Bhatia MS, Bhatia S, Gautam P, Saha R, Kaur J. Burden assessment, psychiatric morbidity, and their correlates in caregivers of patients with intellectual disability. East Asian Arch Psychiatry 2015;25:159-63.

22. Cramm JM, Nieboer AP. Psychological well-being of caregivers of children with intellectual disabilities: Using parental stress as a mediating factor. J Intellect Disabil 2011;15(2):101-13.

23. Chou YC, Fu LY, Lin LC, Lee YC. Predictors of subjective and objective caregiving burden in older female caregivers of adults with intellectual disabilities. Int Psychogeriatr 2011;23:562-72.

24. Raina P, O'Donnell M, Rosenbaum P, Brehaut J, Walter SD, Russell D, et al., The health and well-being of caregivers of children with cerebral palsy. Pediatrics 2005;115:626-36.

25. Narayan CL, John T. The Rights of Persons with Disabilities Act, 2016: Does it address the needs of the persons with mental illness and their families. Indian J Psychiatry 2017;59:17-20.

26. Kashyap K, Thunga R, Rao AK, Balamurali NP. Trends of utilization of government disability benefits among chronic mentally ill. Indian J Psychiatry 2012;54:54-8.

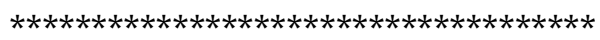

Acknowledgements - Nil.

Conflict of Interest - Nil

Funding - this study was funded by the Indian Council of Medical Research (ICMR) as a part of the short term studentship (STS) program. 